\title{
One more (editorial) for the road
}

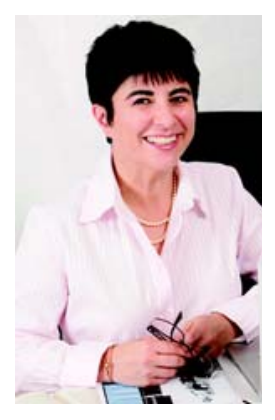

Annette Katelaris

Editor

akatelaris@mja.com.au doi: 10.5694/mjall.cl205 n keeping with tradition, the Christmas double issue, although heavier to carry, takes a lighter approach than usual. Inside, you will read about some of the issues serious and less so - that can affect our enjoyment of the festive season.

The downsides of alcohol consumption are accentuated at Christmas time, especially for teenagers and young adults. The finding by Kisely and colleagues (page 690) that the introduction of the alcopops tax did not significantly alter the number of alcohol-related harms in young people seems surprising. But the authors reflect on several plausible explanations for their findings; the most convincing is that raising the price of only one type of alcohol does not reduce overall alcohol consumption.

In a Letter to the Editor, Doran et al (page 660) demand the urgent reform of alcohol taxation and pricing, and lament the omission of this issue from the recent Australian Government national tax forum held in Canberra on 4-5 October 2011. As the authors say, "too many Australians drink too much alcohol too often". They argue that it is well established that the most effective method of alcohol control is to increase the price of all alcohol through volumetric taxation.

We know that about $80 \%$ of alcohol consumed by people aged 14-24 years is done at risky or high-risk levels for acute harm (http://ndri.curtin.edu.au/local/docs/pdf/naip/ naipaaifullreport.pdf). Alcohol is implicated in more than 60 medical conditions (Babor T, et al. Alcohol: no ordinary commodity. New York: Oxford University Press, 2003) including cancer (MJA 2011; 194: 479-482) and almost one in four road fatalities (http://www.rta.nsw.gov.au/ roadsafety/downloads/crashstats2009.pdf). We have an obligation to protect our youth that we are yet to completely meet.

We continue our Christmas custom of publishing articles on "bites and stings" with an interesting editorial by Kimble et al (page 635) on dog bites in children and their prevention, and research by Mills and colleagues (page 673) on an approach to rabies vaccination for Australian travellers. The case report by Garg et al (page 704) on propeller and jet-ski injuries during the Christmas season may dampen your enthusiasm for motorised water sports. For the keen fisherpeople in our profession, the case reports by Tran and colleagues (page 706) and Sanli and Danks (page 708) on ocular injuries from fishing may make you consider including safety goggles for your tackle box on your Christmas wish list.

Read "Christmas Crackers" for a light-hearted take on some serious issues. Mollison's (page 720) account of the suffering he endured from his self-inflicted mushroom poisoning may lead the mycophagists among you to add "be wary of ingesting wild mushrooms" to your catalogue of Christmas cautions.

Lee and colleagues (page 723), winners of this year's Christmas competition with their article on wife carrying, recommend a novel method of getting more exercise. Something to consider as an alternative to the traditional postprandial snooze on Christmas Day!

I wish you moderation in all good things, a hearty dose of Penguinius collectionavidus infection (Kester, page 730), and a happy, healthy and restful festive season. Thank you for your support this year. We at the MJA look forward to working with you in 2012.

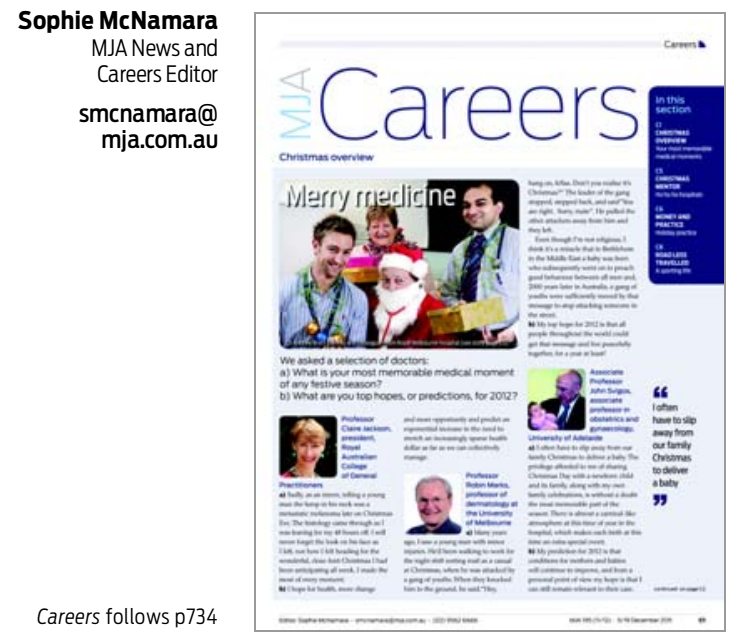

\section{Merry Medicine}

Christmas has come early to the MJA Careers section, with a feast of festive stories to enjoy. We asked a variety of doctors to nominate their most memorable Christmas moments, which included everything from a nursing home gastro outbreak, to delivering babies while dressed as Santa (page C1). We've also tracked down some hospital staff who have a serious case of festive fever (page C5).
And because many of us tap into our sporty side during the summer season, we've spoken to one of Australia's sports medicine legends for the Road Less Travelled section. $\mathrm{He}^{\prime}$ s treated everyone from cricketers Sir Donald Bradman and Richie Benaud to long-distance runner Ron Clarke. Read his incredible story on page C8. 